
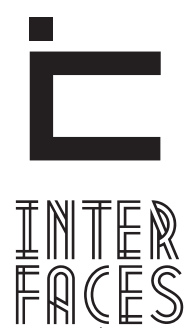

CIENTÍFICAS

EDUCAÇÃO

\title{
DOS CASTIGOSE DA DISCIPLINA: PRÁTICAS ESCOLARES NO TERRITÓRIO SUL SERGIPANO
}

Laísa Dias Santos ${ }^{1}$

Raylane Andreza Dias N. Barreto ${ }^{3}$

\section{RESUMO}

O presente trabalho tem como objeto de análise a trajetória de vida da professora Maria Eurides da Silva de 81 anos de idade, residente no município de Itabaianinha, estado de Sergipe. Com o objetivo de entender como se compôs sua prática de formação buscamos, na narrativa de sua história de vida, os respaldos que possam vir a explicar tanta representatividade local. Para alcançarmos nosso objetivo, recoremos à metodologia da história oral, segundo Montenegro (2010), e a categoria de análise Poder Disciplinar de Foucault (1975; 1979), por meio dos quais pudemos verificar que o que dá sustentabilidade à representação da nossa personagem é o seu método de ensino que permitiu inculcar comportamentos e condutas reconhecidas e aceitas por todos os que, direta ou indiretamente, privaram de seus ensinamentos.

\section{PALAVRAS-CHAVE:}

Práticas de Formação. Castigos. Memória.
Rony Rei do Nascimento Silva²

\section{ABSTRACT}

This paper aims to analyze the life of the teacher Maria Eurides da Silva, she's 81 years old, and lives in Itabaianinha, Sergipe. In order to understand her teaching practice, we investigated her life story, trying to find the data which could explain her local representation. In order to achieve our goal, we recall the methodology of oral history, according to Montenegro (2010) and the analysis category of Disciplinary Power of Foucault $(1975,1979)$, which allowed us to verify that the aspect that give sustainability to the representation of our character is the method of education, since it can instill accepted behaviors and conducts, recognized by all who, directly or indirectly, were influenced by her teaching practices.

\section{KEYWORDS:}

Teaching Practice. Punishment. Memory. 


\section{RESUMEN}

Este trabajo tiene como objetivo el análisis de las historias de vida de la maestra María Eurides da Silva, que tiene 81 años de edad, con domicilio en la ciudad de Itabaianinha, Estado de Sergipe. Con el fin de entender cómo se compuso su práctica docente, buscamos en la narrativa de la historia de su vida el apoyo que podría explicar tal representación. Para lograr nuestro objetivo, se recurre a la metodología de la historia oral, de acuerdo con Montenegro (2010) y la categoría de análisis del poder disciplinario de Fou-

\section{INTRODUCÇ̃̃O}

Minha banca funcionava como uma escola, o aluno entrava no Abc e saia na quarta série. Só iam pra o Grupo tirar o diploma.

(Maria Eurides da Silva)

A autora da epígrafe acima é Maria Eurides da Silva, professora aposentada de 81 anos de idade que reside na cidade de Itabaianinha, interior de Sergipe. Professora de "banca" por cerca de 60 anos, orgulha-se por ter moldado comportamentos e inculcados conhecimentos em várias gerações de alunos a partir de uma formação intelectiva resumida ao quarto ano primário. De fato, não é nenhuma novidade, sobretudo para a história da educação, que, no início do século $X X$, os alunos que soubessem ler e escrever poderiam se tornar professor. $\mathrm{Na}$ verdade, o que nos chamou à atenção foi a forma como a nossa personagem, através de uma banca, entendida aqui como um espaço em que a educação é ministrada por alguém de forma autônoma, ou seja, sem qualquer vínculo com uma instituição educativa, organizou as disposições culturais, econômicas, políticas e sociais próprias de um tempo e espaço e uniu-as à cultura e práticas escolares inerentes à subjetividade do seu eu, formando e educando alunos por várias décadas. cault $(1975,1979)$ a través del cual, pudimos comprobar que lo que sostiene la representación de nuestro personaje es su método de educación que permite inculcar comportamientos, conductas reconocidas y aceptadas por todos los que, directa o indirectamente, son privados de sus enseñanzas.

\section{PALABRAS CLAVE:}

Práctica de Enseñanza. Castigo. Memoria.
Sua ação pedagógica fez da sua "banca" um espaço que ofertou uma educação "parecida” à difundida em instituições educativas legitimadas, visto que, era lá em sua casa, segundo ela, que o aluno fazia todo o primário e só tinha contato com a escola para receber o certificado de conclusão do primário. Se existia uma educação institucionalizada na cidade, por que os pais preferiam colocar seus filhos na banca da professora Eurides? 0 que leva a banca da professora a ser reconhecida como a mais famosa da cidade? Por que sua imagem como professora nunca se apagou da lembrança dos seus ex-alunos, pais e sociedade de Itabaianinha em geral? Quais métodos foram capazes de sustentar sua representatividade que já ultrapassa seis décadas? Que dispositivos contribuíram para a construção desse método? Em quais lugares, tempos e sujeitos, podemos encontrar os vestígios que deram face à sua prática de formação? Tais respostas foram alcançadas a partir de duas entrevistas com a professora realizadas respectivamente no dia 27 de outubro de 2011 e 24 de fevereiro de 2012, na sua residência, Rua Benjamim Constant, $\mathrm{n}^{\circ} 161$, na cidade de Itabaianinha. Juntamente com seu depoimento oral, incluímos na nossa pesquisa relatos de pessoas que direta ou indiretamente tiveram contato com a banca da pro- 
fessora Eurides e dentre manchas de sombra e zonas de luz encontramos na memória de ex-alunos, pais de alunos, a figura de uma professora "rígida", "disciplinar" e "autoritária".

Antônio Torres Montenegro (2010), ao trabalhar com a metodologia da história oral, concebe os entrevistados, através das suas narrativas, autores da sua própria história que permitem ao pesquisador descobrir novos sentidos da realidade, o que se faz não através da repartição daquilo que já se sabe e sim da acumulação do que já é sabido com às lembranças e percepções de indivíduos que ainda não deram a ler os fragmentos da sua memória. Ao conferir status de fonte oral a pontos de vista individual, podemos tornar a história animada porque ela possibilita estabelecer, na entrevista, um contato direto entre entrevistador e entrevistado que pode escutar a história na primeira pessoa e apreciar o passado a distância por meio das lembranças evocadas da memória.

Eclea Bosi (1993), em seu livro Memória e Sociedade: Lembranças de velhos, entende a memória como algo que [...] permite a relação do corpo presente com o passado contudo, [...] o simples fato de lembrar o passado, no presente, exclui a identidade entre as imagens de um e de outro, e propõe a sua diferença em termos de ponto de vista (BOSI, 1993, p. 55). Dessa forma, percebemos que a lembrança, refletida pelos valores do presente, é resultado de uma hibridização de passado e presente que, ao se entrelaçarem no ato de rememorar, formam um emaranhado heterogêneo de valores, princípios e disposições que povoam tanto nossa consciência atual como o nosso inconsciente formado no passado. Sendo assim, ambos (passado e presente) perdem sua essência: não se concebe o passado tal qual como foi, o que se cria são representações sociais sobre ele. Segundo Chartier (1990) podemos entender as representações sociais como "[...] dando a ver uma coisa ausente, o que supõe uma distinção radical entre aquilo que representa e aquilo que é representado" (CHARTIER, 1990, p. 20). De fato não podemos resgatar e muito menos reviver o passado, sobretudo porque não podemos nos apropriar diretamente de algo tão distante. Sendo assim buscarmos compreendê-lo através de imagens, sons, sentidos, percepções que povoam hoje a memória de pessoas que viveram e construíram essa a história do passado. São lugares, tempos, pessoas, objetos materializados no passado longínquo que só podem ser acessados e compreendidos num presente próximo através da ação de rememorar.

Com imagens do presente, a professora Eurides usou da memória para dar a ler os acontecimentos do passado, sobretudo das suas vivências no interior da sua banca escolar. Justino Pereira de Magalhães (2004), através da sua obra Tecendo Nexos: história das instituições educativas, nos possibilita compreender que a banca da professora Eurides assumiu e realizou funções de uma escola, ou seja, de uma instituição educativa legitimada que é capaz de reproduzir culturas ao mesmo tempo em que cria uma cultura própria capaz de conferir-lhe uma identidade histórica. Seja como uma banca escolar, ou seja, como uma escola, como ela mesmo assevera, o que devemos levar em consideração é o fato de seu modo de educar ter moldado comportamentos e inculcado conhecimentos nas pessoas que direta ou indiretamente privaram de seus conhecimentos num tempo e num espaço específicos. Através de uma cultura escolar e de práticas escolares, organizadas em consonância com dispositivos sociais, culturais e ideológicos da época e da ação da professora que se confunde com os conteúdos, com a disciplina, com o horário e com currículo, sua banca torna-se um "organismo vivo". Parafraseando Magalhães (2004)

\footnotetext{
As instituições educativas, como pessoas, são portadoras de uma memória e de memórias. Essas memórias-representações, frequentemente assentes na transmissão oral, revelam-se fixistas, cíclicas, fruto de olhares particulares e consubstanciam-se em relatos dispersos, memórias factuais e justificativas de destinos de vida, marcados não raro por arbítrios e exageros de vária ordem. (MAGALHÃES, 2004, p. 27)
} 
Entender, através de lembranças, narrativa e subjetividade, os mecanismos que faziam e sustentavam sua banca escolar é entender a trajetória de vida da nossa professora, que fez de seu ambiente escolar para além de polo que recebia uma influência determinante da realidade, uma estrutura escolar própria que apresentava, segundo Magalhães (2004), uma internalidade complexa e identitária, que foi elaborada através de uma prática de formação adquirida pela professora Eurides, em partes, por sua mãe Belarmina Pereira da Silva e mais nitidamente com sua professora primária Maria dos Anjos Neres Dias. Como uma herança que permeou a construção de sua identidade e posteriormente de sua banca escolar, sua prática de formação calcada na disciplina sustentou sua representatividade por mais de 6 décadas.

Se ainda atuasse como professora ela acharia por bem usar de castigos físicos e punições para educar seus alunos como fez na época em que ensinava. Mesmo com a Lei Imperial de 15 de outubro de 1827 que, entre diversas prescrições, incidiu a proibição dos castigos físicos nas escolas, substituindo-os pelo de cunho moral, os professores ainda desenvolviam essa prática mesmo que os dispositivos legais ditassem o contrário a exemplo de professora Eurides, que, começando a ensinar em 1945, ainda usava de castigos físicos ratificando a premissa de que as ações não ocorriam na velocidade que pretendia a lei o, que explica a repercussão dos castigos físicos ainda no cotidiano das escolas do século XX. Na verdade, o que se sobressaiu aos novos dispositivos legais foram as experiências acumuladas que deram origem e sus- tentaram o ser professor. Parafraseando Marilda Silva (2003), em sua obra "Como se ensina e como se aprende a ser professora", o modo de ser professora seria estruturado a partir das experiências que o/a professo/a vivenciou enquanto aluno/a, desde a sua tenra idade. Assim, a autora entende que nas experiências vividas na sala de aula durante a escolarização encontram-se as raízes ou vestígios da lógica, da lógica de um habitus professoral que implica diretamente na natureza da didática.

Ao desenvolver práticas escolares antitéticas às estabelecidas por dispositivos legais, ao mesmo tempo que eram aceitas e difundidas pela sociedade, a professora Eurides atuava respaldada num método que tinha razão e sentido de ser, seja numa época, num lugar ou numa cultura. O castigo e a punição compunham o "poder disciplinar" que se revelava não só no campo escolar mais também, parafraseando Michel Foucault (2010), os diversos polos disciplinares, como por exemplo, o convento, o exército, a fábrica, as prisões, o hospital, o hospício. Presente nesse conjunto de instituições disciplinares, Foucault (2010), entende poder disciplinar como"[...]um poder que, em vez de se apropriar e de retirar, tem como função maior 'adestrar'; ou sem dúvida adestrar para retirar e se apropriar ainda mais e melhor" (FOUCAULT, 2010 p. 164). Essa ação dever ser capaz de desenvolver habilidades, comportamentos e atitudes que marquem a personalidade do aluno, devendo ser preparado, habilitado e condicionado a agir de tal forma que desenvolva o efeito esperado pelo professor não só na escola como também no seio familiar e na sociedade.

\section{APRENDER OU APRENDER, EIS AS ALTERNATIVAS}

Maria Eurides da Silva, filha de José Barbosa dos Santos e Belarmina Pereira da Silva, nasceu no dia 03 de setembro de 1931. Natural de São Cristóvão, mudou-se com seus pais e mais oito irmãos para Itabaia- ninha ainda quando criança. Lembra-se em relato que a vida de uma família em que o patriarca é soldado é incerta e como ela mesma afirma, "filha de soldado né, hoje aqui amanhã aculá”. Até os sete anos de 
idade brincar de "boneca, de esconder, de circo e de pular corda” era sua única ocupação, porém sua mãe decide matriculá-la na escola. Entre brincar e estudar, Eurides ingressa na "Escola Pública N 1" de Itabaianinha, sendo aluna da professora Maria dos Anjos Neres Dias.

Na escola da professora Maria dos Anjos, todo mundo tinha que estudar muito: nas carteiras meninos de um lado e meninas de outro, pois, "não juntava menino com menina de jeito nenhum". Os alunos aprendiam a ler, a escrever e a contar regidos por uma disciplina entendida por Foucault (2010) como algo que "fabrica indivíduos", ou seja, o aluno membro de uma sociedade e de uma família deixa de existir e dentro de um polo disciplinar passa a ser fabricado por um "poder modesto, desconfiado e permanente" que é exercido pelo professor. Ao entender a disciplina como "a técnica específica de um poder que toma os indivíduos ao mesmo tempo como objetos e como instrumentos de seu exercício" (FOUCAULT, 2010 p. 164), percebe-se que o aluno era tido como objeto de um exercício de poder: ao mesmo tempo em que toma o próprio aluno como objeto de dominação, tornava-o ele mesmo aparelho de autodisciplinamento.

Eurides estudou apenas o primeiro ano primário com a professora Maria dos Anjos passando ainda pelo ensino das professoras "Maria Letícia", que lecionou o segundo e terceiro ano, e professora "Regina”, que iniciou o quarto ano primário mais faleceu logo após começá-lo, o que ocasionou o abandono escolar da nossa personagem e consequentemente não conclusão da quarta série. Ela lembra que o modo de educar das professoras "era o mesmo", porém Maria Letícia e Regina não eram tão "rígidas" quanto Maria dos Anjos; elas "castigavam menos". Foi a partir desse momento que a nossa personagem deixa de ser aluna e passa a ser a professora segundo ela, "tão rígida quanto Maria dos Anjos de quem herdei tal característica”.

\section{DAS PRÁTICAS E DA DISCIPLINA: “PORQUE EU APRENDI ASSIM"}

Logo que saiu da escola primária, devido à morte da professora Regina, Eurides precisava trabalhar, pois seu pai havia falecido e sua mãe, viúva, teve que sustentar 8 filhos. Como sua mãe não podia "lhe dar as coisas”, Eurides, "dos 13 para 14 anos de idade” e com o primário incompleto, começa a lecionar e, sem se esquecer dos ensinamentos da sua professora predileta, Maria dos Anjos, "monta" uma banca escolar em sua casa. A princípio com um aluno, seu sobrinho "Adelvan", e posteriormente com "80 crianças da cidade". Sobre isso afirma:

Comecei a ensinar cedo. [...] agora comecei com meu sobrinho Adelvan. Quando ele saiu daqui de casa, aí uma mulher ia passando... Eurides tá ensinando? - Eu digo: tô. - Quantos alunos tem? eu digo: - só tenho um, por enquanto. Aí, a mulher mandou duas netas. Aí foi chegando aos poucos, foi chegando aos poucos, até oitenta. (SILVA, 2011, S/p)

Muitas crianças da cidade fizeram o primário na banca da professora Eurides, que, apesar de não receber oficialmente o nome de escola, realizava as mesmas funções de uma, sobretudo no que diz respeito à organização, as condições materiais e de funcionamento, à gramática escolar, o horário, a capacidade de gerar as mais diversas manifestações de saberes, valores e comportamentos. Apesar de a sua ação educativa ser desenvolvida mediante protocolos informais, sua "banca" não era vista nem aceita pela sociedade como uma educação não legitimada e muito menos não institucionalizada: as crianças da cidade, segundo pais de alunos que fizeram o primário com a 
nossa entrevistada, "estudavam na 'escola' da professora Eurides”. Por certo, esse reconhecimento não se restringia apenas à sociedade civil em geral: os dispositivos legais, como a prefeitura, as coordenações das escolas também aceitavam essa designação, pois aceitavam que os alunos que tivessem concluído o primário com a professora Eurides pudessem ser matriculados no ginásio. Sua banca, segundo ela, funcionava dentro de casa. E acrescenta,

\begin{abstract}
Ensinava aqui dentro de casa. Também não tinha nada não, só era banco. Aqui era banco, aí no corredor não tinha cadeira, não tinha mesa, não tinha nada, eu não tinha nada... era só banco. Só tinha mesa de eu escrever e os alunos escreviam nas pernas e eu escrevia na mesa. Mãe dizia: - olhe, se quebrarem uma cadeira, rasgarem um caderno, uma coisa aqui dentro de casa, você apanha! ( SILVA, 2011, S/p)
\end{abstract}

Montar uma banca escolar dentro de casa não foi bem uma escolha da jovem Eurides e sim uma consequência das condições financeiras em que vivia. Para quem não queria passar por dificuldades econômicas como as de uma menina do interior, pobre, negra e de família humilde sustentada pela mãe, trabalhar era uma atitude necessária e que deveria ser adotada. Sua mãe, entretanto, era muito rígida, o que talvez se explique pelo fato de ter cuidado de nove filhos sozinha, não querendo que a filha formasse uma banca dentro de casa, afinal um adolescente não teria como controlar tanta criança sem que não "virasse bagunça'. Além disso, talvez, para a mãe, a filha não tivesse uma personalidade forte para educar e corrigir condutas, papel fundamental de um professor. Contudo, como relembra nossa personagem, sua mãe Belarmina os "[...] criou debaixo da porrada e do castigo, para não nos criarmos malandros", o que nos leva a afirmar que a sua rigidez em sala de aula tenha sido, possivelmente, também herdada de sua mãe.

A "banca escolar" da professora Eurides funcionava, segundo ela, como uma escola, pois o aluno ingressava no primeiro ano e saia no quarto ano e, como ela mesma assevera, "só iam pra o Grupo tirar o diplo- ma”. Na sua banca, os alunos aprendiam desde o $A B C$ até os conteúdos mais difíceis como as disciplinas de Matemática, Português, Ciências e História. Lembra-se perfeitamente das maneiras como ministrava essas disciplinas, por exemplo, o português: segundo ela, quando o aluno ingressava na sua "escola":

[...] dava logo as notas às mães, do $A B C$ e um caderno e um lápis e pronto. Agora, pra eles aprenderem o $A B C$, decorar, [eu] furava um papel e perguntava: - que letra é essa? Pra eles decorar e saber. - Que letra é essa? Se não soubesse... apanhava. Dava a cartilha. 0 nome da cartilha era cartilha do Povo, Cartilha Nacional. Eles cobriam letras; eu fazia e eles cobriam pra aprender a fazer as letras... né. ( SILVA, 2011, S/p)

O que se pôde arrestar foi que, ao ensinar do mesmo jeito que aprendeu, Maria Eurides não só se apropriou dos conteúdos disciplinares como do modus operandi de sua professora. E, em outras palavras, dos seus modos de educar. Assim, parafraseando Faria Filho e Vidal (2004) as práticas escolares se revelam "[...] produtoras de sujeitos e de seus respectivos lugares no interior do campo pedagógico" e que "[...] tais práticas produzidas pelos sujeitos no seu dia-a-dia escolar, também os produzem" (FARIA FILHO E VIDAL, 2004, p. 151). Sendo assim, apreendemos que as práticas escolares, por vez, fruto de uma cultura escolar e de singularidades locais, têm dentre suas funções a de despertar no aluno a necessidade de absorver conhecimentos, além de delinear condutas a ponto de fazer com que o aluno conduzido (re)construa, a partir desse princípio, seus hábitos, sua conduta e até sua identidade, que segundo Hall (2005) apud Mesquita (2008), é produzida dentro de locais históricos e institucionais, no interior de formações e práticas discursivas, por estratégias e iniciativas específicas.

Por certo, compreender as práticas utilizadas pela professora Eurides na sua "banca escolar" como fruto de uma cultura escolar é reconhecer a professora Maria dos Anjos como depositária e disseminadora de práticas educativas específicas de uma instituição de 
ensino que se constituiu através de sistemas culturais, políticos e sociais que caracterizavam uma época que também contou com estratégias e iniciativas próprias da professora. Como uma herança produzida e perpassada, as práticas, o castigo e a disciplina, fizeram parte da vida de seus alunos e mais especificamente dos 60 anos de ensino ministrado pela professora primária Maria Eurides da Silva e que compõem a maior parte de sua trajetória de vida.

Ao ensinar do mesmo modo que aprendeu, professora Eurides lembra que a sua professora Maria dos Anjos era muito "rígida" e que, por ensinar "do mes-

\subsection{ENTRE PRÁTICAS, DISCIPLINA E CASTIGO: “NA MINHA BANCA A LEI ERA ESCREVEU NÃO LEU, O PAU COMEU"}

A educação ofertada por nossa personagem era repleta de recursos, segundo ela, necessários e indispensáveis a um bom aprendizado e consequentemente a um bom comportamento. Eram instrumentos simples que garantiam o sucesso do poder disciplinar. 0 primeiro deles era a forma como se distribuía os alunos no espaço, onde deveria ser ofertada a educação: todos sentados em bancos, um atrás do outro, eram distribuídos de acordo com o grau de escolaridade; os menores ficavam mais perto da professora e os mais adiantados ficavam mais afastados, ou seja, como a escola era na sua casa, o birô ficava na cozinha junto com os alunos de $A B C$ e os demais ficavam na sala e nos corredores, "porque não precisavam de tanta atenção assim, eles já sabiam ler”. Distribuídos pela casa, que não tinha móveis nenhum, cada banco servia de assento para mais ou menos 8 crianças do mesmo sexo, "os meninos de um lado e as meninas de outro, porque eu aprendi assim... não foi? - então tem que ser igual como eu aprendi”. (SILVA, 2011, S/p).

Distribuídos em sala de aula e regidos por um horário, cada aluno era controlado por atividades que respectivamente se resumiam a mo jeitinho que ela ensinava, eu também saí assim, rígida!". Usando da disciplina, aprendida no ambiente escolar da professora Maria dos Anjos como técnica de poder, a professora Eurides sustenta até hoje sua representatividade ancorada no olhar que vigiava, nos castigos físicos que puniam e no exercício que controlava. Sendo assim, ao usar da lembrança para rememorar as experiências vividas na sua "banca escolar" e usando de representações sociais para dar a ver uma "coisa ausente" através da linguagem, a professora Eurides nos permite contemplar em entrevista o "fascínio do vivido", refeito por imagens atuais, porém sem perder suas mais importantes lembranças.

Para além das distribuições espaciais e temporais, a professora Eurides usava de outras ferramentas para lidar com a difícil tarefa de educar 80 alunos de uma só vez: era o olhar que vigiava e disciplinava. Segundo Foucault (2010), a vigilância hierárquica é aquela em que o olho perfeito seria àquele a que nada escapa e se torna o centro ao qual todos os olhares convergem. Ao apenas "passar o olho", como ela mesma diz, os alunos percebiam que estavam exercendo práticas consideradas pela professora indevidas e ela não precisava usar de palavras para repreendê-los. Seu olhar disciplinador era tão temido que não se resumia apenas aos alunos da sua "banca escolar" como ela mesma rememora. 
[...]quando uma amiga minha se mudou pra aqui, eu fui visitá-la na casa dela. Chegando lá tinha uma menina, aí a mãe disse: - vá pra fonte Maria José, vá buscar água. A menina disse não vou! Então eu olhei pra ela e disse: - sua mãe não tá mandando você ir pra fonte não? - O que é que você tá fazendo que ainda tá aí? Ela baixou a cabeça e saiu com tudo. Aí a menina disse: - quando acabar mamãe a senhora quer botar eu com essa mulher, Deus me livre!. A mãe mandou... ela não foi. Foi só eu passar o olho... ela foi, (hahahaha). ( SILVA, 2011, S/p)

Não foi preciso gritar, usar de violência, muito menos castigar, bastou apenas um olhar de uma pessoa que já era conhecida indiretamente pela criança por sua rigidez. Além do seu olhar que vigiava e disciplinava direta e indiretamente a sociedade de Itabaianinha, ela usava de outra forma de vigiar, pois, como ela mesmo afirma, "era difícil dar conta de 80 alunos". A partir da boa conduta e do bom desempenho escolar, a professora Eurides nomeia "Jandira e Arnaldo", seus mais exemplares alunos, para ajudá-la a vigiar, ensinar e fiscalizar a sala de aula com o intuito de informá-la sobre quem estava praticando atitudes incorretas como travessuras, brincadeiras e desatenção, ao mesmo tempo que serviam para tomar a lição dos alunos menos adiantados.

Apesar de estarem sobre uma rígida vigilância hierárquica, os alunos ainda apresentavam um comportamento considerado, pela professora, indevido e sempre tinha alguém que continuava a "pintar e bordar". A essas crianças, ela dedicava o castigo como "micropenalidade" de comportamento, ou seja, de uma má conduta. Trata-se, segundo Foucault (2010), de "[...] tornar penalizáveis as frações mais tênues da conduta dando uma função punitiva" capaz de fazer com que as crianças sintam a falta que cometeram. Desse modo, ao colocar os alunos faltosos "de joelho nos caroços de milho, com os braços abertos, presos depois da aula, em pé atrás da porta”, podia, segundo ela, fazer com que o aluno se arrependesse do que havia feito de errado, o que muitas das vezes garantia que o aluno não iria voltar a cometer a falta.

Para além do mau comportamento, os castigos também eram usados para punir quem chegava atrasado, quem não dava a lição ou não respondia a atividade, àquelas pessoas desatentas e desobedientes, que não tinham postura ao se sentar, ou até mesmo aquelas que não possuíam um boa dicção, como foi o caso de uma aluna que não conseguia pronunciar a palavra "pescoço". Segundo Eurides:

Os meus alunos tinham que soletrar, e era bem soletrado. Porque tem gente que não sabe soletrar... né? Ói... teve uma aqui mesmo, que ficou presa. A mãe veio apanhar. Eu digo: - tá presa por causa desse nome "pescoço". Soletre! ela fazia: - percoço. -Percoço? -Você tá vendo um "r" aí? É pescoço! vamos soletre! Ficou presa. Eu disse a mãe: - deixe ela presa... para aprender a falar. (SILVA, 2011, S/p)

Na sua a banca a lei era, "escreveu não lei o pau comeu" e, como toda lei deve ser seguida, os alunos tinham que adaptar suas condutas às regras impostas na banca escolar ou iriam ficar de castigo. A professora Eurides não perdoava nenhum deslize dos alunos, ou seja, por mais que um comportamento fosse insignificante e contrário às suas normas, ela usaria da punição disciplinar. Sobre sua intransigência ela exemplifica:

[...] tinha um menino aqui, que tinha um costume né (balançar a cabeça). Eu digo: -você vai deixar esse costume menino! Mas não era... não era costume não. Ele era doente e eu pensava que era malandragem dele, aí botei ele em pé. Quando eu vi. ele tava desmaiando. Aí... chega!!! Peguei ele e botei sentado. Dei água e aí nunca mais voltei a botar ele de castigo. Ele balançava a cabeça demais. Eu... - menino! não balance a cabeça Gilson! E ele, balançando a cabeça. Gilson vá estudar, Gilson! E ele com a cabeça balançando, pois nesse dia você vai ficar em pé aqui. Pra que eu botei?... pronto! Aí ele ficou balançando a cabeça. Até hoje ele balança a cabeça. Ele é casado, já tem filho, e continua balançando a cabeça. (SILVA, 2011, S/p)

Os castigos que tinham a função de reduzir os erros e a punição como algo que pudesse fazer com que as crianças se arrependessem da falta que tinham cometido também se apresentavam, na "banca escolar" da professora Eurides, por beliscões, puxão de orelha, 
tapas, reguadas e pela palmatória, considerada por Souza (2007), como uma cultura material escolar. Ela estava presente nas sabatinas, processo pelo qual o aluno era arguido pelo professor e aquele que não soubesse a resposta da pergunta que havia sido feita, levava os chamados "bolos" nas mãos, às vezes, por outro aluno que tivesse acertado a resposta ou até mesmo pelo próprio professor como forma de castigo por não ter estudado a lição e consequentemente errado a resposta.

Lembra saudosa que, mesmo passados tantos anos seus ex-alunos, não esquecem a professora primária e apesar de ficarem "presos" (de castigo) depois da aula, como ela afirma, eles conservam uma grande gratidão à professora que foi o "alicerce da vida deles". Todos os alunos, segundo ela, que passaram por sua "banca escolar" tiveram um futuro próspero e aqueles em que ela não conseguiu inculcar conhecimentos e moldar comportamentos através do seu poder disciplinar tiveram um futuro não muito promissor, como ela mesmo relata

[...]só teve um aqui que eu não consegui castigar. Quando eu ia deixar ele de castigo o pai chegou e pediu pra eu soltar. Eu disse: - não posso soltar ele. Ah.. mais já vai dar duas horas! Aí eu disse: - quando chegar meu horário, eu sei também, que eu tenho relógio dentro de casa... Esse daí deu pra marginal, bandido danado, porque o pai não queria que castigasse. (SILVA, 2011, S/p)

A disciplina não era exercida apenas sobre aluno; os pais também eram envolvidos nessa teia de poder a fim de garantir que o comportamento inculcado fosse eficiente. Assim sendo, a forma e a relação de confiança que os pais depositavam no professor garantia a ele, nesse caso, a ela, uma autoridade suprema capaz até de delimitar se o aluno seria um bom ou mau indivíduo, pois como afirma nossa professora, "eu era a lei" e acrescenta "[...] pai bom era aquele que chegava aqui e eu dizia: - tão preso! E ele dizia: -pronto, solte na hora que a senhora quiser!". Tal depoimento nos leva a perceber que esse tipo de atitude descarta- va todo e qualquer impeditivo às suas práticas educativas. Dessa maneira, a professora Eurides fez fluir um comportamento desejado e mediado, segundo ela, pelo seu "espaço escolar". Parafraseando Foucault (2010), o seu espaço tornar-se-ia “[...] uma máquina de ensinar, mas também de vigiar, de hierarquizar, e de recompensar".

A educação ofertada pela professora Eurides fez-se presente não só na sua banca escolar mais também foi reconhecida por uma instituição educacional do município, denominada Escola Municipal Passos Porto, pela qual, depois de 15 anos ensinando em sua "banca escolar", foi convidada em 1960 para fazer parte do quadro de professores da instituição e aceitando o emprego levou consigo para sala de aula todos os alunos de sua banca, que passaram a ter uma educação institucional pela manhã e uma educação não institucional ofertada em sua "banca" à tarde. Depois, por desavenças políticas, a professora Eurides passa a trabalhar como servente, contudo apenas no "papel" visto que seu compromisso selado com os pais e com os alunos que a conheciam e estudavam na sua banca fundada em 1945 fez com que ela não saísse da sala de aula e que continuasse a usar do mesmo modo de educar que usava na sua banca com exceção dos castigos porque, segundo ela, "lá não tinha direito de castigar, não tinha palmatória, não tinha régua, não tinha nada. Se der a lição deu, se não deu vá embora". Privada do castigo, um instrumento de execução do seu poder disciplinar, a professora Eurides nos conta que controlar os alunos sem castigar não teria sido fácil se “[...] a maioria não tivesse saído daqui (da banca) pra lá, pois os outros vendo os modos daqui aprendiam e se comportavam igual". 


\section{CONCLUSÃO}

Ao buscar compreender como se compôs sua prática de formação, a fim de explicar tal representatividade, chegamos à conclusão que as respostas das nossas inquietações estavam presentes no seu método de ensino que pode ser revelado através das lembranças-narradas. Na medida em que desvelamos seu método de ensino, encontrávamos os respaldos que sustentam sua representatividade, tais quais, o olhar hierárquico, a sanção normalizadora e o exame. Sua prática de formação calcada em métodos de ensino que puderam ser compreendidos na sua narrativa de história de vida, sobretudo no que diz respeito à sua construção identitária, revelaram uma herança moral, cultural e ideológica deixada por sua mãe, Belarmina Pereira da Silva e sua professora primária Maria dos Anjos Neres Dias, ambas, segundo ela, responsáveis pela sua ação pedagógica.

\section{REFERÊNCIAS}

BRANDÃO, Zaia. Pesquisa em educação: conversas com pós-graduandos. Rio de Janeiro: PUC-Rio; São Paulo: Loyola, 2002.

BOSI, Ecléa. Memória e Sociedade: Lembrança dos Velhos. 3. ed. São Paulo: Companhia das Letras. 1993.

CHARTIER, Roger. A História Cultural: entre práticas e representações; Rio de Janeiro, 6. ed. Bertrand Brasil.1990.

FOUCAULT, Michel. Microfísica do poder; organização e tradução de Roberto Machado- Rio de Janeiro: Edições Graal, 1979;

FOUCAULT, Michel. Vigiar e punir: nascimento da prisão; tradução de Raquel Ramalhete. 38. ed. Petrópolis, Rj: Vozes, 2010.
Seus métodos de ensino faziam de sua prática de formação e consequentemente de sua banca escolar uma "instituição educativa" reconhecida e aceita tanto pela sociedade civil como pelos dispositivos legais, como as instituições educativas legitimadas do município. Sendo assim, marcando uma época e um espaço sua representatividade local hoje é sustentada por pedaços de suas práticas escolares, fruto de uma prática de formação, incorporadas por seus alunos e mantida dentro deles como uma parte da identidade dos adultos que hoje são, pois seu método de ensino calcado no poder disciplinar foi capaz de se fazer presente no subconsciente e essa presença acabou por fincar-se no interior de cada um, a ponto de não sair nunca mais.

FREITAS, Fabiano Junqueira de; BRAGA, Paula Lou Ane Matos Braga. Questões introdutórias para uma discussão acerca da história e da memória. Revista Histórica, n. 13, p. 1, 2006.

MAGALHÃES, Justino Pereira de. Texendo nexos: história das instituições educativas. Bragança Paulista: Editora Universitária São Francisco, 2004.

MESQUITA, Ilka Miglio. Memórias/identidades em relação ao en sino e formação de professores de História: diálogos com fóruns acadêmicos nacionais. 2008. Tese Doutorado em Educação. Universidade Estadual de Campinas, São Paulo. 2008.

MONTENEGRO, Antonio Torres. História oral e memória: a cultura popular revisitada. 6.ed., São Paulo: Contexto, 2010; 
SILVA, Marilda. Como se ensina e como se aprende a

ser professora. Bauru/São Paulo: EDUSC. 2003.

Recebido em: 13 de julho de 2012

Avaliado em: 23 de julho de 2012

Aceito em: 6 de agosto de 2012
1 Graduanda em Serviço Social, aluna de Iniciação Científica/ Programa de Bolsas de Iniciação Científica-PROBIC e membro do Grupo de Pesquisa Sociedade, Educação, História e Memória- GPSEHM. E-mail: laisadias10@ gmail.com

2 Graduando em Serviço Social, componente do Colegiado do curso de Serviço Social/Unit, aluno de Iniciação Científica/ Programa Voluntário de Iniciação Científica-PROVIC, membro do Grupo de Pesquisa Sociedade, Educação, História e Memória- GPSEHM. E-mail: ronysocial@hotmail. com. Endereço: Brasil: Itabaianinha-Sergipe, Travessa Odorico Alves dos Santos, $n^{\circ} 36$. Telefone: 07998097184

3 Doutora em Educação pela Universidade Federal do Rio Grande do Norte (UFRN); Mestre em Educação e bacharel em Ciências Sociais pela Universidade Federal de Sergipe (UFS). Professora PPG 1 da Universidade Tiradentes e líder do Grupo de Pesquisa Sociedade, educação, história e memória. E-mail: raylane_navarro@unit.br 